\title{
Effective Desiliconization Method with Swirling Flow of Hot Metal at Blast Furnace Casthouse
}

\author{
Yu-ichi UCHIDA, ${ }^{1) *}$ Yasuo KISHIMOTO, ${ }^{2)}$ Yuji MIKI, ${ }^{3)}$ Tetsuro UCHIDA, ${ }^{4)}$ Ryuji TSUTSUMI ${ }^{4)}$ and \\ Tomoyuki UENO ${ }^{5}$
}

1) Formerly Steelmaking Research Department, Steel Research Laboratory, JFE Steel Corporation. Now at Nippon Institute of Technology, 4-1 Gakuendai, Miyashiro-machi, Saitama, 345-8501 Japan.

2) Formerly Steelmaking Research Department, Steel Research Laboratory, JFE Steel Corporation. Now at Ministry of Education, Culture, Sports, Science and Technology, Chiyoda-ku, Tokyo, 100-8959 Japan. $\quad 3$ Steelmaking Research Department, Steel Research Laboratory, JFE Steel Corporation, 1 Kokan-cho, Fukuyama, Hiroshima, 721-8510 Japan. 4) Ironmaking Department, East Japan Works (Chiba), JFE Steel Corporation, 1 Kawasaki-cho, Chiba, Chiba, 260-0835 Japan. 5) Steelmaking Department, East Japan Works (Chiba), JFE Steel Corporation, 1 Kawasaki-cho, Chiba, Chiba, 260-0835 Japan.

(Received on January 13, 2016; accepted on March 8, 2016; originally published in Tetsu-to-Hagané, Vol. 101, 2015, No. 9, pp. 471-478)

\begin{abstract}
Hot metal desiliconization is carried out by adding iron oxide at a tilting runner in a blast furnace casthouse to improve BOF operation. Aiming at effective silicon removal by enhancing mixing of desiliconizing agent and hot metal, desiliconization experiments at an actual blast furnace casthouse was performed with the tilting runner that was specially designed to generate swirling flow of hot metal.

1. Amount of silicon removed from the hot metal through the entire desiliconization operation was larger under the swirling flow condition of hot metal compared with conventional non-swirling one.

2. Hot metal samples taken at the exit of the tilting runner showed that change in silicon content of hot metal in the tilting runner was larger with swirling condition.

3. Hot metal samples were also taken from the torpedo car, and desiliconization behavior in a transient basin part of the torpedo car was evaluated. Calculated silicon content in the basin part was lower with swirling condition.

4. A reaction analysis was made assuming that present system is a semi-batch reactor. Reaction rate constant of desiliconization through the swirling part of the tilting runner and the basin part of the torpedo car was 2.2 times higher with swirling condition. This result qualitatively agrees with the results of previous 5 ton hot metal experiments and reflects enhanced mixing of desiliconizing agent and hot metal by swirling flow in an industrial-scale operation.
\end{abstract}

KEY WORDS: blast furnace; casthouse; desiliconization; hot metal; swirling flow; tilting runner.

\section{Introduction}

Reduction of silicon content of molten pig iron has many advantages, such as reduction of time required in hot metal dephosphorization, improvement of dephosphorization efficiency and resulting lower phosphorus input at the converter, and reduction of slag generation. Desiliconization of molten pig iron is commonly carried out at a blast furnace casthouse for process convenience. Generally, iron oxide-containing material is added as a desiliconizing agent to the molten pig iron at a tilting runner above a receiving vessel (transfer ladle or torpedo car). ${ }^{1,2)}$ The desiliconization reaction with iron oxide is denoted as follows:

$$
\underline{\mathrm{Si}}+2 \mathrm{Fe}_{\mathrm{x}} \mathrm{O}=\mathrm{SiO}_{2}+2 \mathrm{xFe}
$$

In order to increase amount of removed silicon, one can increase amount of desiliconizing agent and/or enhance desiliconization efficiency. However, increasing amount of

\footnotetext{
* Corresponding author: E-mail: yuichi.uchida@nit.ac.jp DOI: http://dx.doi.org/10.2355/isijinternational.ISIJINT-2016-023
}

desiliconizing agent has several drawbacks, including an increase in the cost of the agent, a decrease in the hot metal temperature, and a decrease in the hot metal weight in the receiving vessel due to slag foaming.

Desiliconizing agent, which originally have $\mathrm{Fe}_{\mathrm{x}} \mathrm{O}$ content of 60-80 mass $\%$, reacts with molten pig iron in the tilting runner and $\mathrm{Fe}_{\mathrm{x}} \mathrm{O}$ content is reduced below 40 mass $\%$ at the outlet of the tilting runner. Desiliconizing agent forms slag, flows into the container, and reacts with the hot metal again due to falling-induced stirring. Final $\mathrm{Fe}_{\mathrm{x}} \mathrm{O}$ concentration in slag is 10 mass $\%$ or less. Therefore, for sufficient silicon removal, reaction of desiliconization with slag having $\mathrm{Fe}_{\mathrm{x}} \mathrm{O}$ concentration, less than 40 mass $\%$, is important after addition of desiliconizing agent.

Several reports, concerning with desiliconization reaction of hot metal with iron oxide, have been published. ${ }^{3-6}$ ) Shibata et al. reported that rate of desiliconization reaction strongly depended on mass transfer of $\mathrm{Fe}_{\mathrm{x}} \mathrm{O}$ in slag based on desiliconization experiment with $120 \mathrm{~g}$ of hot metal. $\left.{ }^{6}\right)$ Thus, promotion of mass transfer of $\mathrm{Fe}_{\mathrm{x}} \mathrm{O}$ in slag in low $\mathrm{Fe}_{\mathrm{x}} \mathrm{O}$ concentration range is a key factor for sufficient sili- 
con removal.

It is generally known that higher temperature and agitation are effective for promoting mass transfer. Several reports have shown the effect of oxygen gas blowing ${ }^{7)}$ and gas injection ${ }^{8)}$ on desiliconization at a blast furnace casthouse. Nakasuga et al. performed desiliconization with impeller stirring at a blast furnace runner. ${ }^{9)}$ However, while these methods may be effective, they have a disadvantage of requiring an installation of special, large-scale equipment.

One alternative is agitation by generating a swirling flow in hot metal itself, which can be realized by the flow of hot metal at a blast furnace casthouse. Inertial force or gravity can be utilized to cause a swirling movement of hot metal. A simple method for imparting swirling movement to fluid is to pass the fluid through a funnel. Papers related to laboratory observation of swirling flow and its application to hot metal desulfurization have been published. ${ }^{10-12)}$ To date, however, no application of this swirling flow technique to desiliconization at an actual blast furnace casthouse has been reported.

In previous work, the authors carried out an investigation on enhancement of mixing of hot metal and desiliconizing agent by a swirling flow with the aim of improving desiliconization efficiency at the blast furnace casthouse. ${ }^{13)}$ Water model experiments were performed as a part of a basic investigation of swirling flow, followed by 5 ton hot metal desiliconization experiments using an experimental vessel with a funnel-shaped device for imparting swirling movement.

As shown in Fig. 1, the experimental setup simulated the flow system at a typical blast furnace casthouse. The experimental vessel, which consisted of a part for blasting desiliconizing agent (blasting part) and a part for swirling hot metal (swirling part), was installed above the container ladle. The vessel corresponds to a tilting runner at a blast furnace casthouse.

Change in hot metal [Si] was evaluated based on sampling of the hot metal at the blasting part and at the container ladle. The results showed enhancement of silicon removal of hot metal in [swirling part + container ladle] with swirling flow of hot metal. Since $\mathrm{Fe}_{\mathrm{x}} \mathrm{O}$ content in the slag sampled at the blasting part was below 42 mass $\%$ in the experiment, these results showed that silicon removal was enhanced by applying the swirling movement to hot metal. Furthermore, detailed analysis of the desiliconization reaction in the basin part of the container ladle, which is a transient region where desiliconization reaction mainly occurs, showed that the mass transfer coefficient of Si in these parts was almost double under the swirling condition compared to that under the non-swirling condition, as shown in Fig. 2.

As outlined above, the possibility of enhancing desiliconization reaction by applying swirling movement to hot metal was confirmed in our previous publication on 5 ton hot metal experiment. In the present paper, the results of a plant trial using a specially-designed tilting runner which generates swirling movement of hot metal with the aim of improving desiliconization efficiency at the blast furnace casthouse is reported. The tilting runner with a funnelshaped device is installed to impart swirling movement and promote mixing of desiliconizing agent and hot metal while passing through the device.

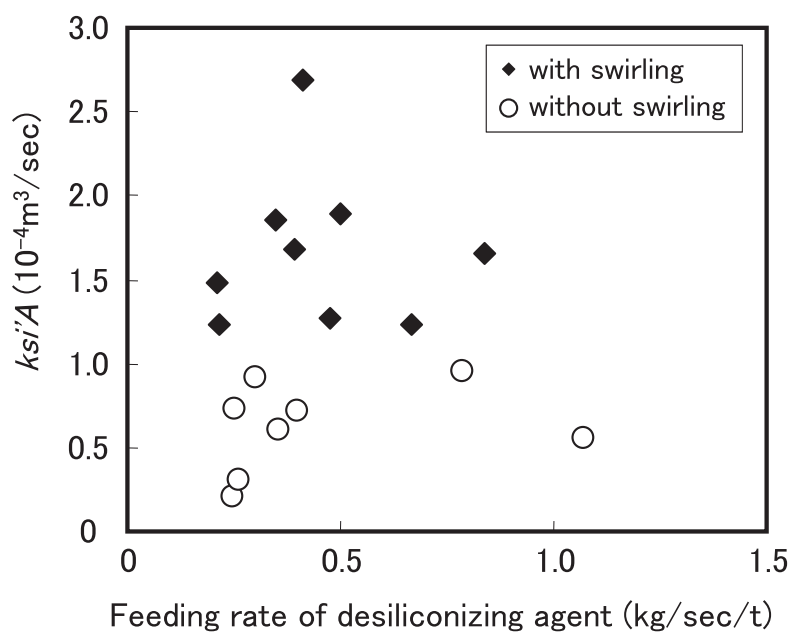

Fig. 2. Relationship between reaction coefficient of desiliconization and feeding rate of desiliconizing agent in 5 ton hot metal desiliconization experiment. ${ }^{13)}$
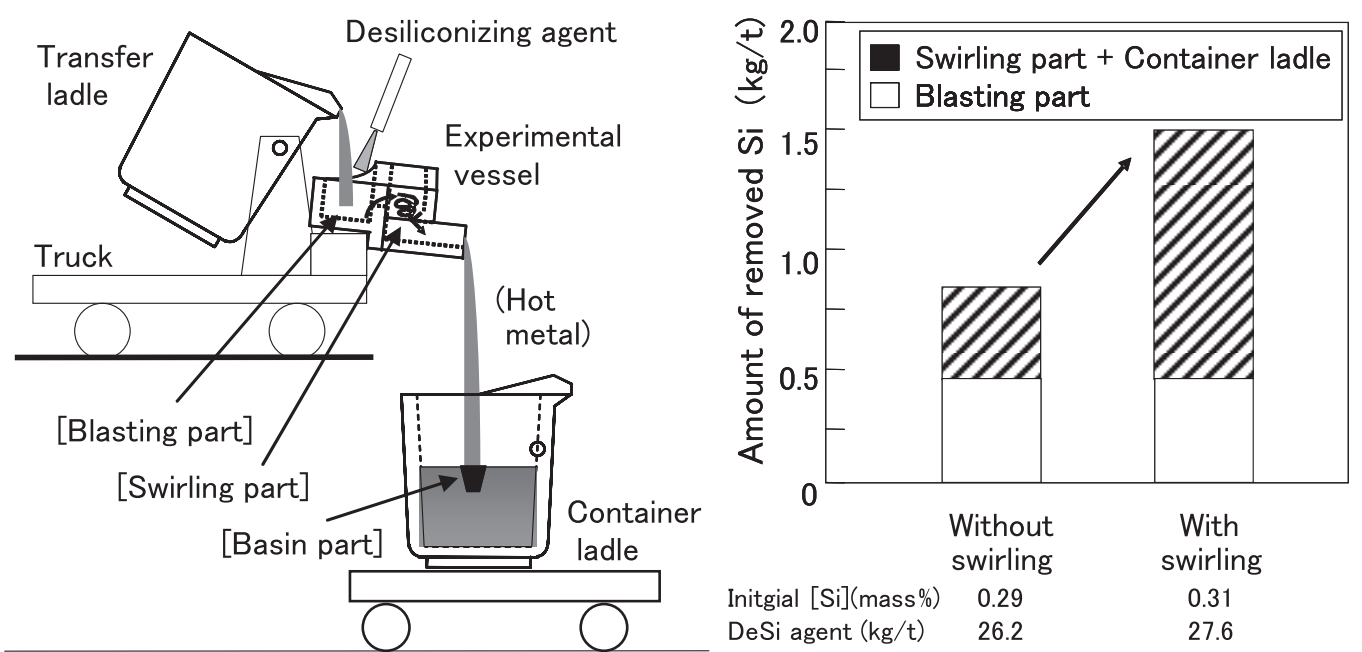

Fig. 1. Schematic illustration of experimental setup and amount of removed $\mathrm{Si}$ in 5 ton hot metal desiliconization experiment. $^{13)}$ 


\section{Experimental Method}

A schematic illustration of the specially-designed tilting runner (hereafter referred as novel tilting runner) employed in the plant trial is shown in Fig. 3. A funnel-shaped device for imparting swirling movement (hereafter referred as swirling part) is installed at the end of the runner, which is partitioned by an inside wall. The inside wall is designed so that hot metal flows eccentrically from a reservoir into the swirling part in order to ensure swirling of hot metal in the swirling part. A path which guides hot metal to a torpedo car is provided under the swirling part.

Diameter of the inside body and the outlet of the swirling part is decided so as to obtain a Swirl number, being in the range of 1.5-2.0, which was the preferable value range in the water model and 5 ton hot metal experiments in our previous publication. ${ }^{13)}$ Swirl number ${ }^{14)}$ in the present experiments is defined as follows:

$$
S=\frac{G_{\theta}}{G_{x} \times d}
$$

where, $G_{\theta}$ is angular momentum of swirling flow $\left(\mathrm{kg} \cdot \mathrm{m}^{2} / \mathrm{sec}\right)$, $G_{x}$ is axial momentum of flow at the funnel outlet $(\mathrm{kg} \cdot \mathrm{m} /$ $\mathrm{sec}$ ), and d is diameter of the funnel outlet. $G_{\theta}$ was calculated from the inlet velocity of the hot metal at the funnel and the radius of the funnel, and $G_{x}$ was derived from the outlet velocity of the hot metal at the funnel under a free fall condition, respectively.

Diameter of the funnel outlet is set to $400 \mathrm{~mm}$ considering the size of skull or slag lumps which might flow through the blast furnace runner. As a result, Swirl number of the tilting runner in this trial is 1.5 at the normal flow rate of hot metal.

The swirling part is installed on a single side of the tilting runner to enable a comparison between swirling condition and non-swirling condition at the same tapping. The length of the tilting runner is the same as that of the conventional one, so there is no change in the trajectory of hot metal flow from the runner. Although the end of the tilting runner is enlarged in downward direction due to the installation of the swirling part and the tilting angle of the runner is limited compared to that in the conventional runner, these differences did not cause any problems in hot metal receiving operation at the torpedo car.

The plant trial of silicon removal using the novel tilting runner was carried out at the blast furnace at East Japan Works (Chiba District) of JFE Steel Corporation. Desiliconization operation was performed for up to 81 hours with the novel tilting runner. The schematic setup of the desiliconization operation at the blast furnace casthouse is shown in Fig. 4. Hot metal comes from the blast furnace runner and flows into the reservoir of the runner. Desiliconizing agent is added to hot metal in the reservoir through a lance (hereafter, this reservoir is referred as the blasting part). Hot metal and desiliconizing agent then flow into the swirling part and fall into the torpedo car. Desiliconizing agent was mill scale or dust having $\mathrm{Fe}_{\mathrm{x}} \mathrm{O}$ content of more than 65 mass\%.

Figure 4 shows a schematic image of desiliconizing and receiving operation at the blast furnace casthouse. Hot metal is received in the torpedo car, followed by addition of desiliconizing agent. After adding the predetermined amount of desiliconizing agent, addition of agent is stopped and receiving of hot metal is continued until the torpedo car is filled.

Hot metal tapped from the blast furnace was sampled for chemical analysis at the blast furnace runner. Hot metal in the torpedo car after desiliconization operation was sampled at the following steelmaking shop. Hot metal samples for chemical analysis were also taken at the exit of the tilting runner using a long sampler and in the torpedo car during desiliconizing operation; these samples were taken several times during a single desiliconizing operation. Sampling at the exit of the tilting runner and in the torpedo car was carried out successively within a short time. In several experiments, slag samples for chemical analysis were also taken from the blasting part.

\section{Experimental Results}

A smooth swirling flow was observed when hot metal was supplied to the novel tilting runner. No blockage by

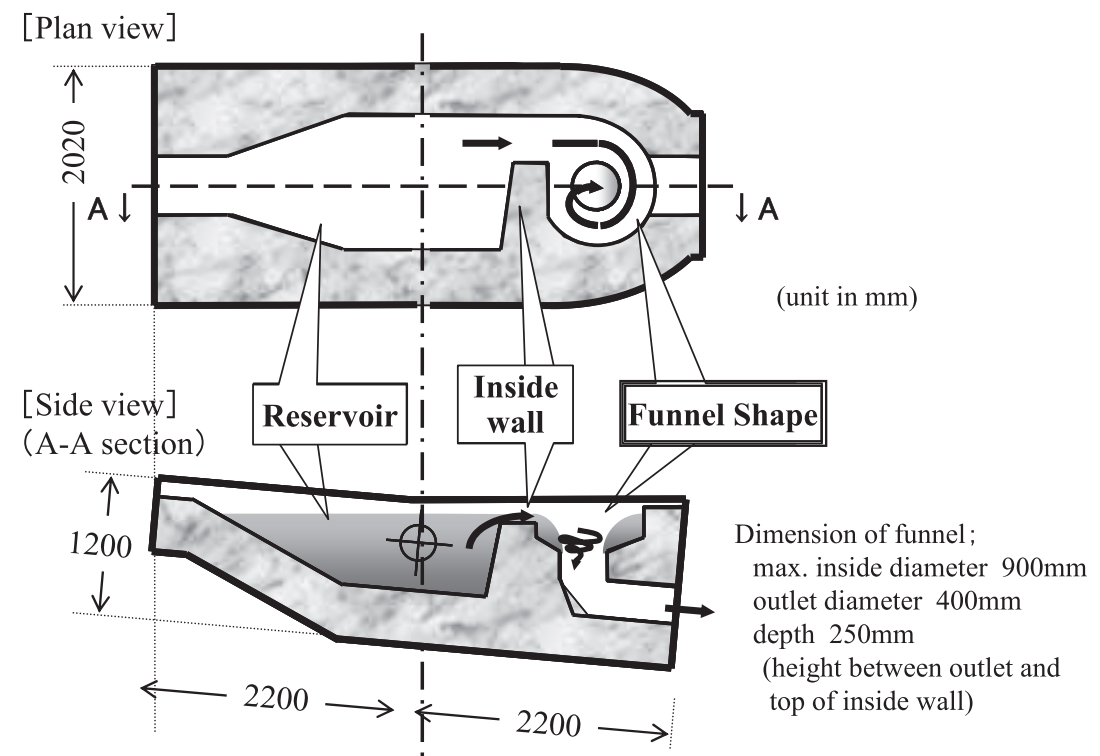

Fig. 3. Schematic illustration of tilting runner to generate swirling flow. 


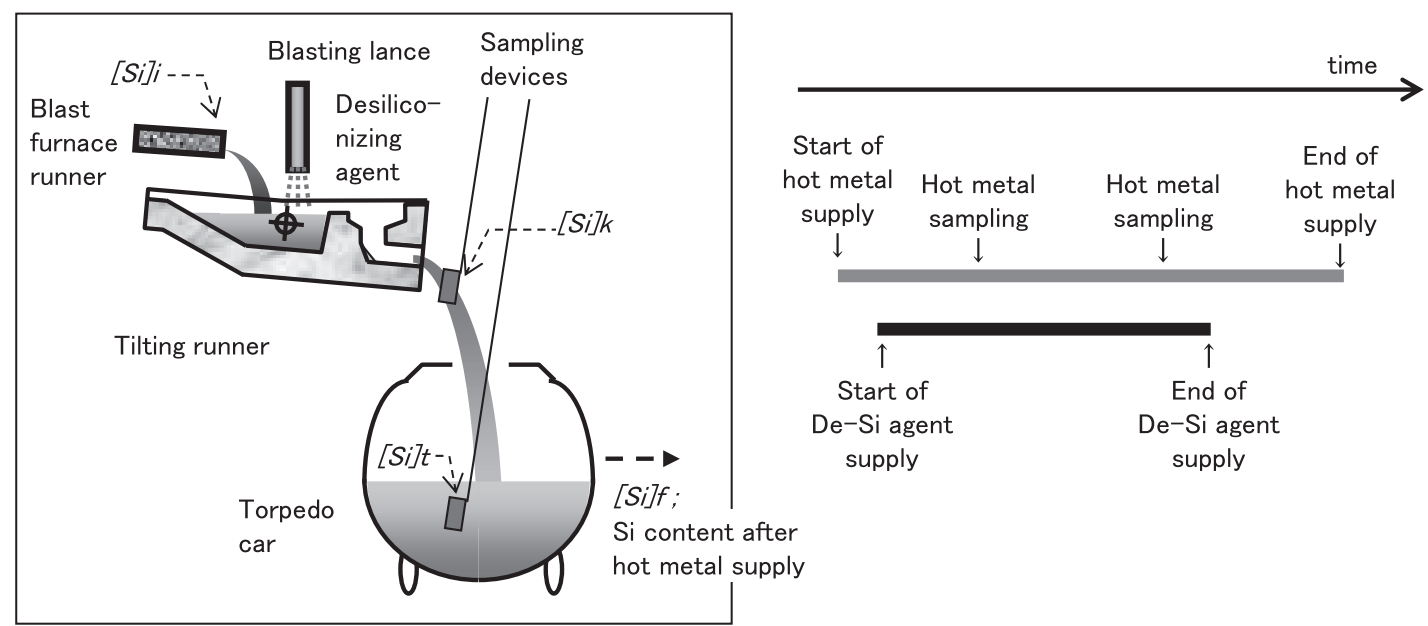

Fig. 4. Schematic illustration of desiliconization operation at blast furnace casthouse.

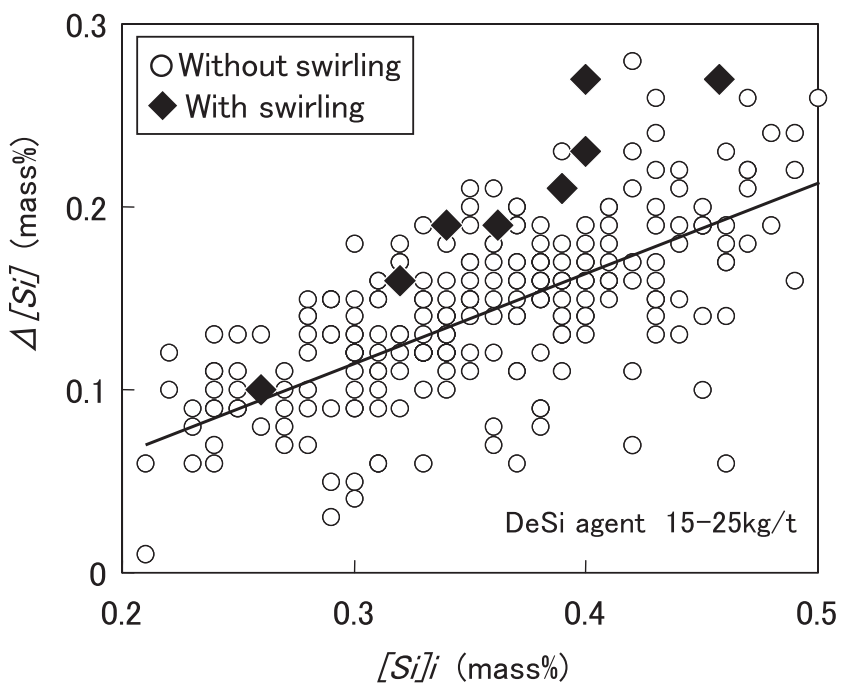

Fig. 5. Relationship between $[S i]_{i}$ and $\Delta[S i]$.

skull or masses of slag at the outlet of the swirling part occurred during the trial. Slag foaming behavior in the torpedo car with the novel tilting runner was similar to that in the conventional operation.

Figure 5 shows the difference, $\Delta[S i]$ (mass\%), between the silicon content of the hot metal immediately after tapping from the blast furnace, $[S i]_{i}(\operatorname{mass} \%)$, and the silicon content of the hot metal in the torpedo car after hot metal receiving operation, $[\mathrm{Si}]_{f}(\operatorname{mass} \%)$. As is clear from the figure, $\Delta[\mathrm{Si}]$ is larger at higher $[\mathrm{Si}]_{i}$. Although data are scattered due to variations in the receiving and desiliconizing condition of hot metal in individual operations, at the same $[\mathrm{Si}]_{i}, \Delta[\mathrm{Si}]$ is larger under the swirling condition compared to the conventional non-swirling condition.

Oxygen efficiency for desiliconization in this trial, $\eta(\%)$, is defined as follows:

$$
\eta=\frac{(\Delta[S i] \times 10 / 28) \times 22.4}{W a \times \psi a} \times 100
$$

where, $W a$ is amount of desiliconizing agent added at the tilting runner ( $\mathrm{kg} / \mathrm{ton})$, and $\psi a$ is amount of oxygen contained in a unit weight of desiliconizing agent $\left(\mathrm{Nm}^{3} / \mathrm{kg}\right)$.

In Fig. 6, various values of $\eta$ are plotted against $[S i]_{i} . \eta$

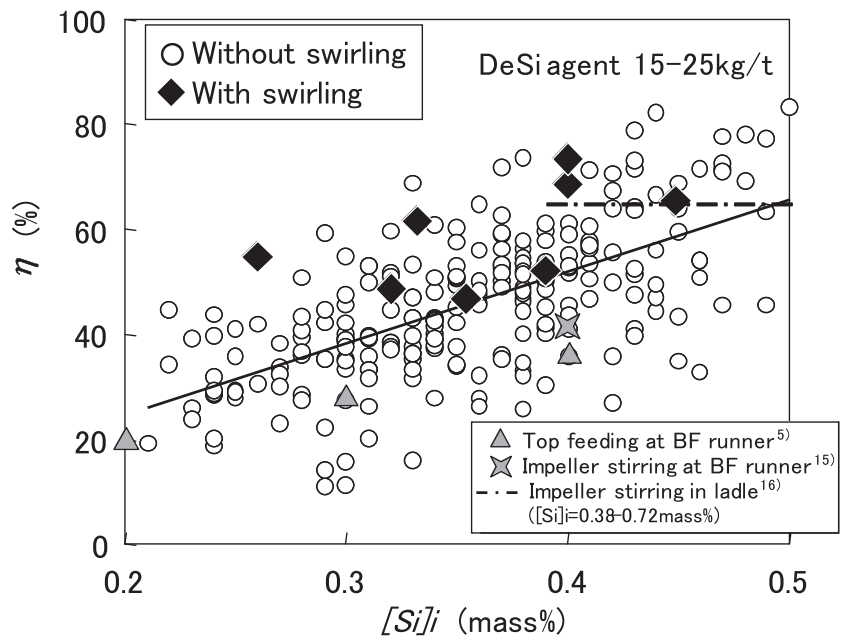

Fig. 6. Relationship between $[S i]_{i}$ and $\eta$.

increases with increasing $[S i]_{i}$ under both the non-swirling and the swirling condition. However, $\eta$ is larger under the swirling condition. The figure also shows the $\eta$ reported in the previous literature. ${ }^{5,15,16)} \eta$ in the present trial is larger than that with impeller stirring at the blast furnace runner and is equivalent to the value with impeller stirring in the transfer ladle.

Silicon content in hot metal sampled at the exit of the tilting runner during desiliconization operation, $[\mathrm{Si}]_{k}$ (mass\%), and silicon content in hot metal sampled in the torpedo car during desiliconization operation, $[S i]_{t}(\operatorname{mass} \%)$, are shown against $[\mathrm{Si}]_{i}$ in Figs. 7 and 8, respectively. These data were obtained at ratios $R a / F(\mathrm{~kg} / \mathrm{t})$ in the range of 15-25, where $F$ $(\mathrm{t} / \mathrm{min})$ is the tapping rate of hot metal during sampling and $R a(\mathrm{~kg} / \mathrm{min})$ is the feeding rate of the desiliconizing agent, both at the time of hot metal sampling.

Amounts of removed Si in the blasting part, the swirling part, and the torpedo car are evaluated from the change in Si content in hot metal sampled at the exit of the tilting runner and in the torpedo car. The results are shown in Fig. 9. Since hot metal sampled at the exit of the tilting runner passed through the swirling part, amount of removed $\mathrm{Si}$ in the blasting part under the swirling condition is estimated based on the analysis described in the following section. Total amount of removed $\mathrm{Si}$ in [swirling part + torpedo 


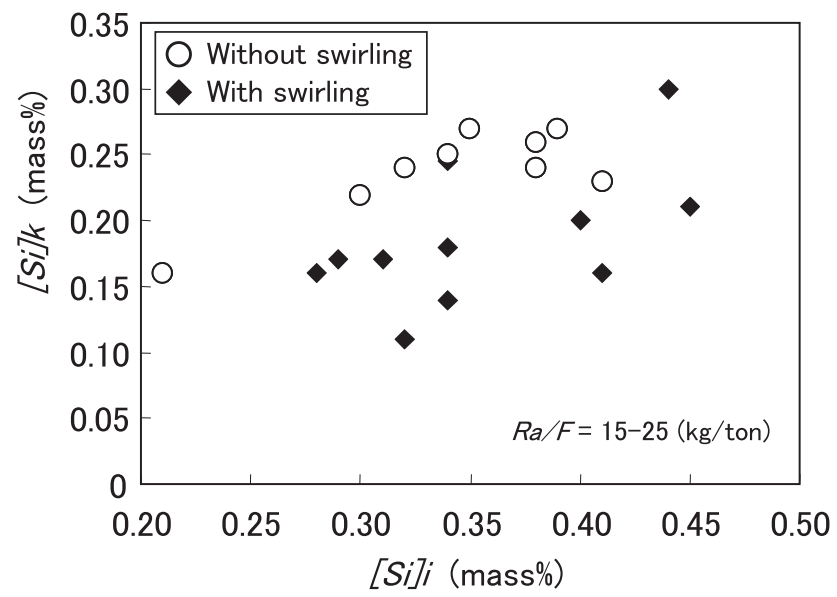

Fig. 7. Relationship between $[\mathrm{Si}]_{i}$ and $[\mathrm{Si}]_{k}$.

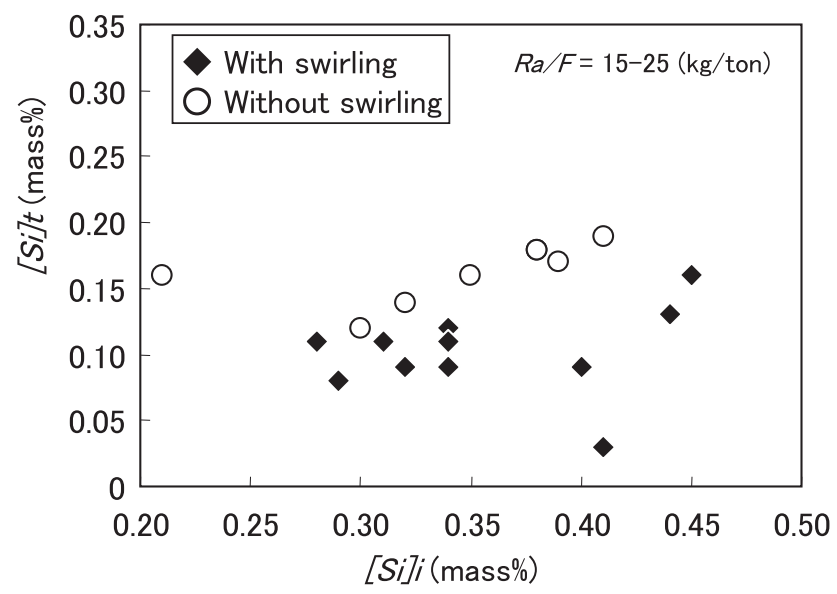

Fig. 8. Relationship between $[S i]_{i}$ and $[S i]_{t}$.

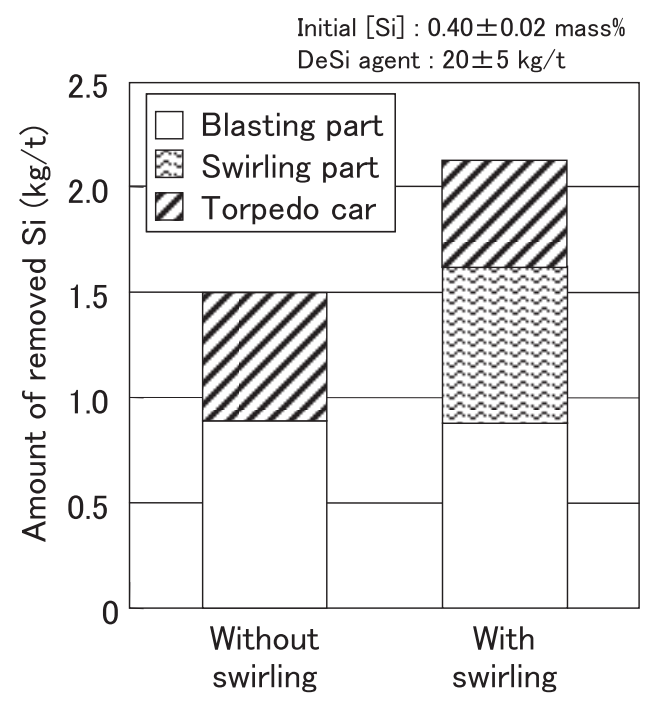

Fig. 9. Comparison of amount of removed Si.

car] under the swirling condition was large, as can be seen from the figure.

$\mathrm{Fe}_{\mathrm{x}} \mathrm{O}$ content in the slag sampled at the blasting part was 22-40 mass\%. Therefore, the results in Fig. 9 reflect the fact that the amount of removed Si increases as a result of the addition of swirling movement, even in the case of the low
$\mathrm{Fe}_{\mathrm{x}} \mathrm{O}$ slag formed after the reaction of desiliconizing agent with hot metal, which corresponds to the previous results. ${ }^{13)}$

\section{Discussion}

The present results show the tendency that the desiliconization reaction is enhanced by imparting a swirling flow to hot metal at the blast furnace casthouse. In the present trial, two parts are considered as reaction sites, the blasting part in the tilting runner and the torpedo car into which hot metal and slag fall in. These are shown schematically in Fig. 10.

Silicon content in the hot metal sampled from the torpedo car can be considered as follows: The hot metal at the exit of the tilting runner flows continuously, which means that $[\mathrm{Si}]_{k}$ reflects desiliconization reaction at the time of sampling. On the other hand, since hot metal which flows into the torpedo car mixes with the residual hot metal in the torpedo car, $[S i]_{t}$ cannot directly represent the desiliconization reaction inside the torpedo car. Therefore, a small virtual region of the hot metal bath where hot metal falls into the torpedo car (basin part) is considered for the purposes of this analysis, as shown in Fig. 10. The basin part is a transient region where hot metal falls into the torpedo car immediately before mixing with surrounding residual hot metal. Silicon content in the basin part is denoted as $[\mathrm{Si}]_{b a}$ (mass\%). Since $[\mathrm{Si}]_{b a}$ is the result of the desiliconization reaction in the basin part with desiliconizing agent after reaction at the tilting runner, it would also reflect an effect of the swirling flow. $\left[\mathrm{Si}_{b a}\right.$ can be evaluated considering the mass balance of silicon in the torpedo car, as shown in the following equation. In this equation, $[\mathrm{Si}]_{b a}$ is calculated based on the assumption that the change in the amount of silicon in the torpedo car occurs only during the duration of blasting of desiliconizing agent.

$$
[S i]_{b a}=\frac{W^{\circ} \times[S i]_{t}^{\circ}+F \times\left(t_{f}-t_{b}\right) \times[S i]_{i}-W^{\bullet} \times[S i]_{t}^{\bullet}}{t_{b} \times F} \ldots
$$

where, $W^{\circ}$ and $W^{\bullet}$ are the weight of the hot metal in the torpedo car (ton) at a certain sampling chance and at the last sampling (or at the beginning of hot metal receiving), respectively, and $[\mathrm{Si}]_{L}{ }^{\circ}$ and $[\mathrm{Si}]_{L}{ }^{\bullet}$ are silicon contents of hot metal in the torpedo car at a certain sampling chance and at the final sampling (or beginning of hot metal receiving), respectively (mass\%). $F$ is the rate of hot metal tapping from the blast furnace (ton/min), $t_{f}$ is the time interval between two successive sampling steps (min), and $t_{b}$ is the time of blasting of the desiliconizing agent ( $\mathrm{min}$ ).

Figure 11 shows the changes in $[\mathrm{Si}]_{i},[\mathrm{Si}]_{k}$, and $[\mathrm{Si}]_{b a}$ with and without the swirling flow of hot metal. The data in the figure were selected from typical experimental conditions of $[S i]_{i}=0.34 \pm 0.04(\operatorname{mass} \%), R a / F=15-25(\mathrm{~kg} / \mathrm{t})$. The data linked by the solid line were obtained at the same timing. As shown in the figure, $[\mathrm{Si}]_{k}$ and $[\mathrm{Si}]_{b a}$ decrease when the swirling movement is applied. Even in the case of higher $[\mathrm{Si}]_{k}$ with swirling, $[\mathrm{Si}]_{b a}$ in the basin part of the torpedo car becomes sufficiently low. This suggests that entrainment of desiliconizing agent into hot metal occurs in the swirling part, and the desiliconization reaction in the basin part is then enhanced by the entrained agent.

Amounts of silicon removed in the tilting runner, $\Delta[S i]_{k}$, and the basin part in the torpedo car, $\Delta[S i]_{b a}$, are shown in 


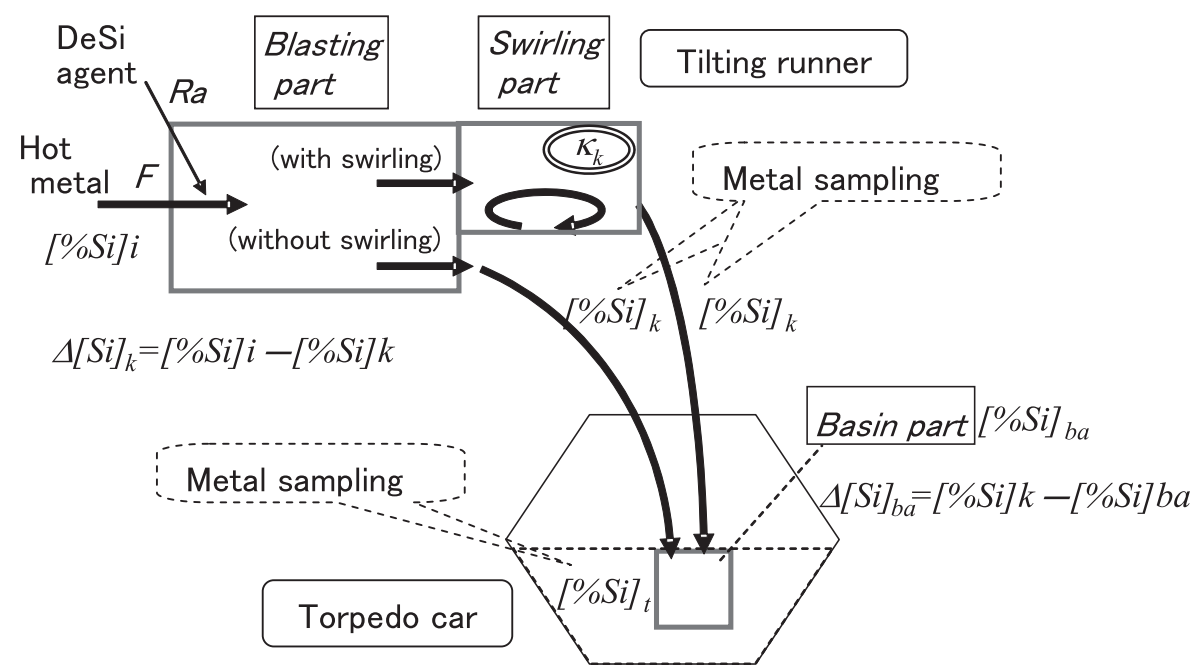

Fig. 10. Schematic model of desiliconization at blast furnace casthouse.

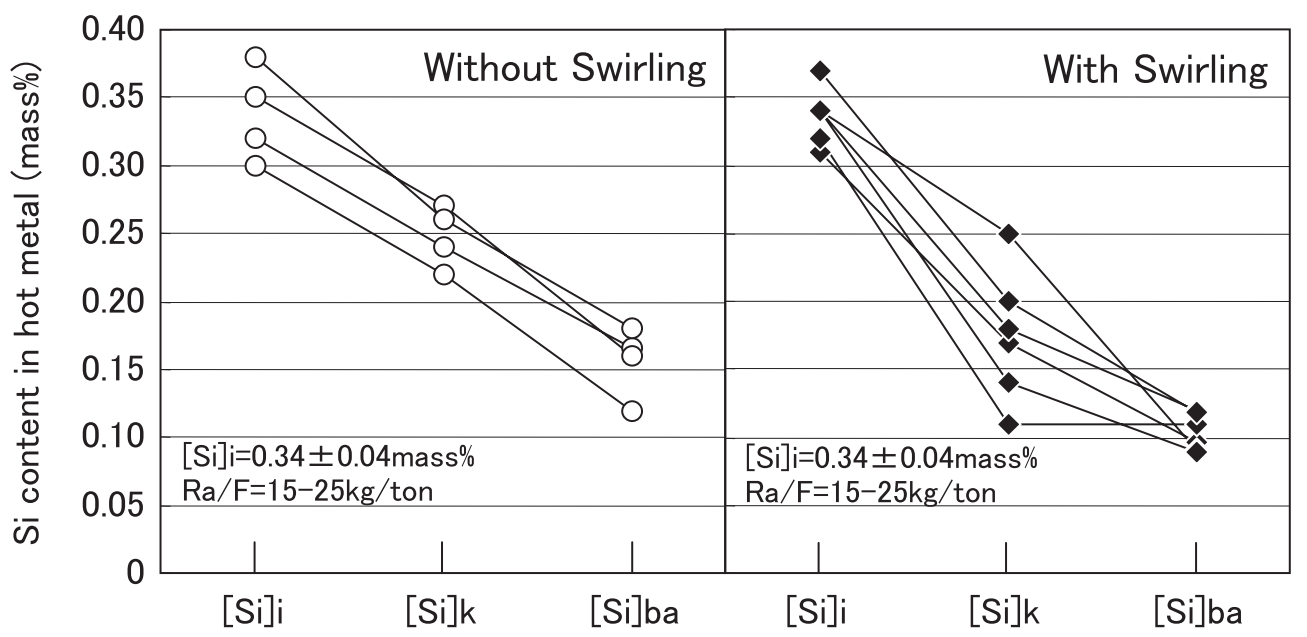

Fig. 11. Change in Si content of hot metal during desiliconization operation.

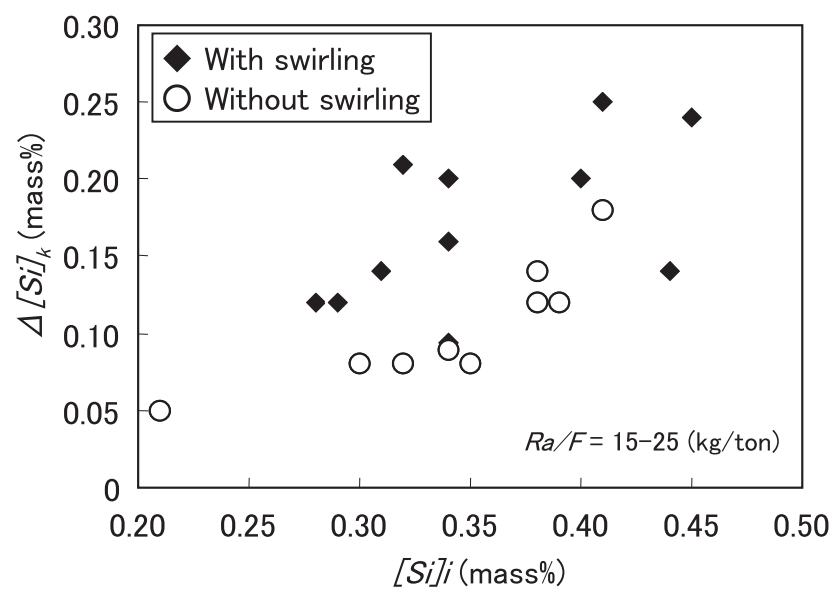

Fig. 12. Relationship between $[S i]_{i}$ and $\Delta[S i]_{k}$.

Figs. 12 and 13, respectively.

$$
\begin{aligned}
\Delta[\mathrm{Si}]_{k} & =[\mathrm{Si}]_{i}-[\mathrm{Si}]_{k} . \\
\Delta[\mathrm{Si}]_{b a} & =[\mathrm{Si}]_{k}-[\mathrm{Si}]_{b a}
\end{aligned}
$$

In Fig. $12, \Delta[\mathrm{Si}]_{k}$ is shown against $[\mathrm{Si}]_{i .} \Delta[\mathrm{Si}]_{k}$ increases with $[S i]_{i}$, which is consistent with the result shown by Mori

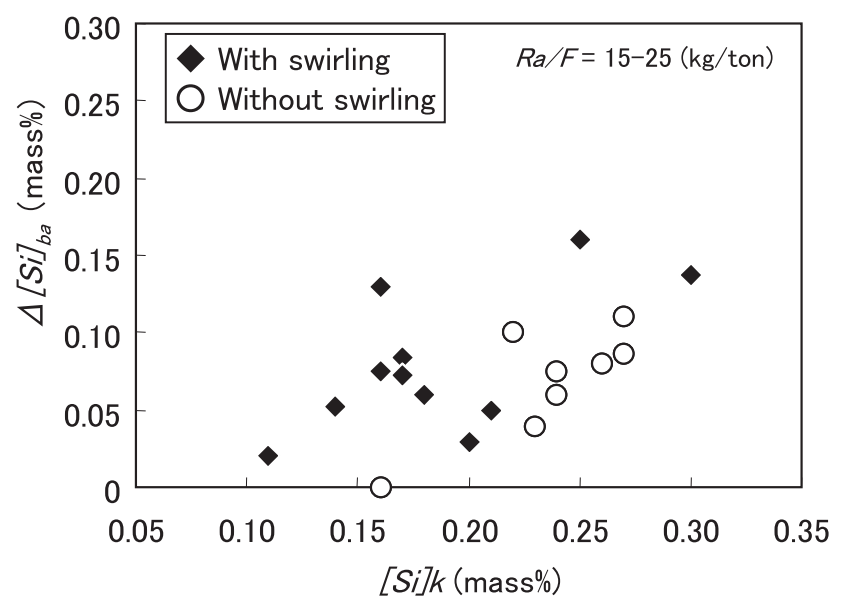

Fig. 13. Relationship between $[S i]_{k}$ and $\Delta[S i]_{b a}$.

et $a l .{ }^{17)}$ Within the present $[S i]_{i}, \Delta[S i]_{k}$ is higher with the swirling flow of hot metal. Figure 13 shows $\Delta[S i]_{b a}$ against $[\mathrm{Si}]_{k} . \Delta[\mathrm{Si}]_{b a}$ is lower than $\Delta[\mathrm{Si}]_{k}$ because desiliconization reaction in the torpedo car is caused by relatively low (T.Fe) slag after the reaction at the tilting runner. Although $[\mathrm{Si}]_{k}$ under the swirling condition is low due to the enhancement of prior silicon removal at the tilting runner, $\Delta[S i]_{b a}$ with 
swirling is not lower compared to that without swirling. These results suggest that desiliconizing agent can make a further contribution to the reaction in the basin part, even after reaction in tilting runner.

The present reaction system can be considered as follows: Hot metal flows into the tilting runner and the torpedo car at a constant flow rate, reacts within a certain residence time, and then flows out. Therefore, the following analysis assumes that the present system is a semi-batch type reactor. ${ }^{18)}$ To start with, the tilting runner which characterizes the present system is analyzed. The mass balance of silicon in hot metal flowing into the tilting runner is denoted by the following equation:

$$
F[S i]_{i}-F[S i]_{k}-r_{k} W_{k}=W_{k} \frac{\mathrm{d}[S i]_{k}}{\mathrm{~d} t}
$$

where, $r_{k}$ (mass $\left.\% / \mathrm{min}\right)$ is the reaction rate, and $W_{k}$ (ton) is the weight of hot metal in the tilting runner.

Provided that the reaction in the tilting runner is steady and $[\mathrm{Si}]_{k}$ does not change, the above equation becomes as follows:

$$
F[S i]_{i}-F[S i]_{k}-r_{k} W_{k}=0
$$

As mentioned above, desiliconization reaction strongly depends on silicon content in the hot metal. Therefore, the following equation can be used, assuming that desiliconization obeys first-order reaction.

$$
\begin{gathered}
r_{k}=\kappa_{k}[S i]_{i} \ldots \ldots . \\
\kappa_{k}=\left(\frac{[S i]_{i}}{[S i]_{k}}-1\right) \cdot \frac{1}{\theta_{k}}
\end{gathered}
$$

where, $\kappa_{k}(1 / \mathrm{min})$ is the reaction rate constant in the tilting runner, and $\theta_{k}(\mathrm{~min})$ is the mean residence time of hot metal in the tilting runner, indicated by $W_{k} / F$.

In Fig. 14, the $\kappa_{k}$ calculated from Eq. (10) is shown against $R a / F$. Even there are some scattering, the tendency of higher $\kappa_{k}$ is apparent under the swirling condition.

It is worth comparing these results and the results of the 5 ton hot metal desiliconization experiment in the previous paper. ${ }^{13)}$ The reaction systems of the 5 ton hot model and the present trial at the actual blast furnace casthouse are shown schematically in Fig. 15. Both system can be considered to consist of the successive semi-batch reactors of the blasting part, the swirling part, and the basin part.

In the hot model experiment, desiliconizing agent was supplied to hot metal in the experimental vessel, hot metal was swirled in the vessel, and hot metal was then received in the container ladle below the vessel. Hot metal was sampled at the blasting part and at the container ladle, but could not be sampled at the exit of the experimental vessel. Therefore, in order to analyze the effect of the swirling flow in the previous experiment, the desiliconization reaction rate constant $\kappa_{e}(1 / \mathrm{min})$ is evaluated as shown by Eq. (11), in which it is assumed that the region from the exit of the blasting part through the basin part of the container ladle comprises one semi-batch reaction zone (enclosed by the dashed bold line in Fig. 15).

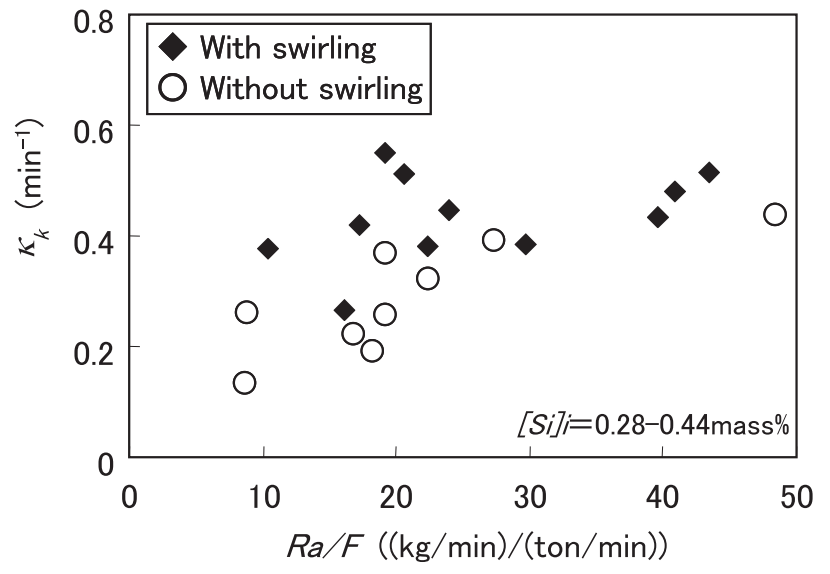

Fig. 14. Relationship between $R a / F$ and $\kappa_{k}$.

$$
\kappa_{e}=\left(\frac{[S i]_{b l}}{[S i]_{b a}}-1\right) \cdot \frac{1}{\theta_{k l}}
$$

where, $[\mathrm{Si}]_{b l}$ and $[\mathrm{Si}]_{b a}$ are silicon contents of the hot metal in the blasting part and the basin part, respectively (mass\%), and $\theta_{k l}$ is mean residence time from the exit of the blasting part through the basin part of the container ladle ( $\mathrm{min}$ ). The result is shown in Fig. 16 against the ratio $R a / F . \kappa_{e}$ is clearly higher under the swirling condition.

The same analysis was made for the present results, assuming that the region from the exit of the blasting part through the basin part of the torpedo car is one semi-batch reaction zone (enclosed by the dashed bold line in Fig. 15). In this analysis, silicon content in hot metal flowing from the blasting part to the swirling part is the initial value of the reaction zone.

$\kappa_{e}$ for the present trial is denoted as follows:

$$
\kappa_{e}=\left(\frac{[S i]_{b l}}{[S i]_{b a}}-1\right) \cdot \frac{1}{\theta_{k t}}
$$

where, $[\mathrm{Si}]_{b l}$ is silicon content of hot metal in the blasting part (mass\%), and $\theta_{k t}$ is mean residence time from the exit of the blasting part through the basin part of the torpedo car (min). $\theta_{k t}$ is evaluated based on the plunging depth of free falling hot metal ${ }^{19,20)}$ as in the previous papers, ranging in the order of $10^{-1}$ second.

Although the hot metal in the blasting part cannot be sampled, it would correspond to hot metal at the exit of the tilting runner without swirling, that is, $[\mathrm{Si}]_{k}$ (without swirling) $=[S i]_{b l}$. Therefore, $[S i]_{k}$ without swirling under various conditions was employed to estimate $[\mathrm{Si}]_{b l}$ by multiple regression.

The result is shown in Fig. 17, which indicate the relationship between $R a / F$ and $\kappa_{e}$. In spite of some scattering of the date, $\kappa_{e}$ tends to be higher under the swirling condition at a same $R a / F$ value.

Since equipment scale (volume or falling height of hot metal) and other conditions (temperature or composition of hot metal) were different among the previous experiment and the present one, it would not be appropriate to compare directly the values of the desiliconization rate constant. Therefore, the increment of the rate constant should be compared from the viewpoint of the swirling effect. In the 

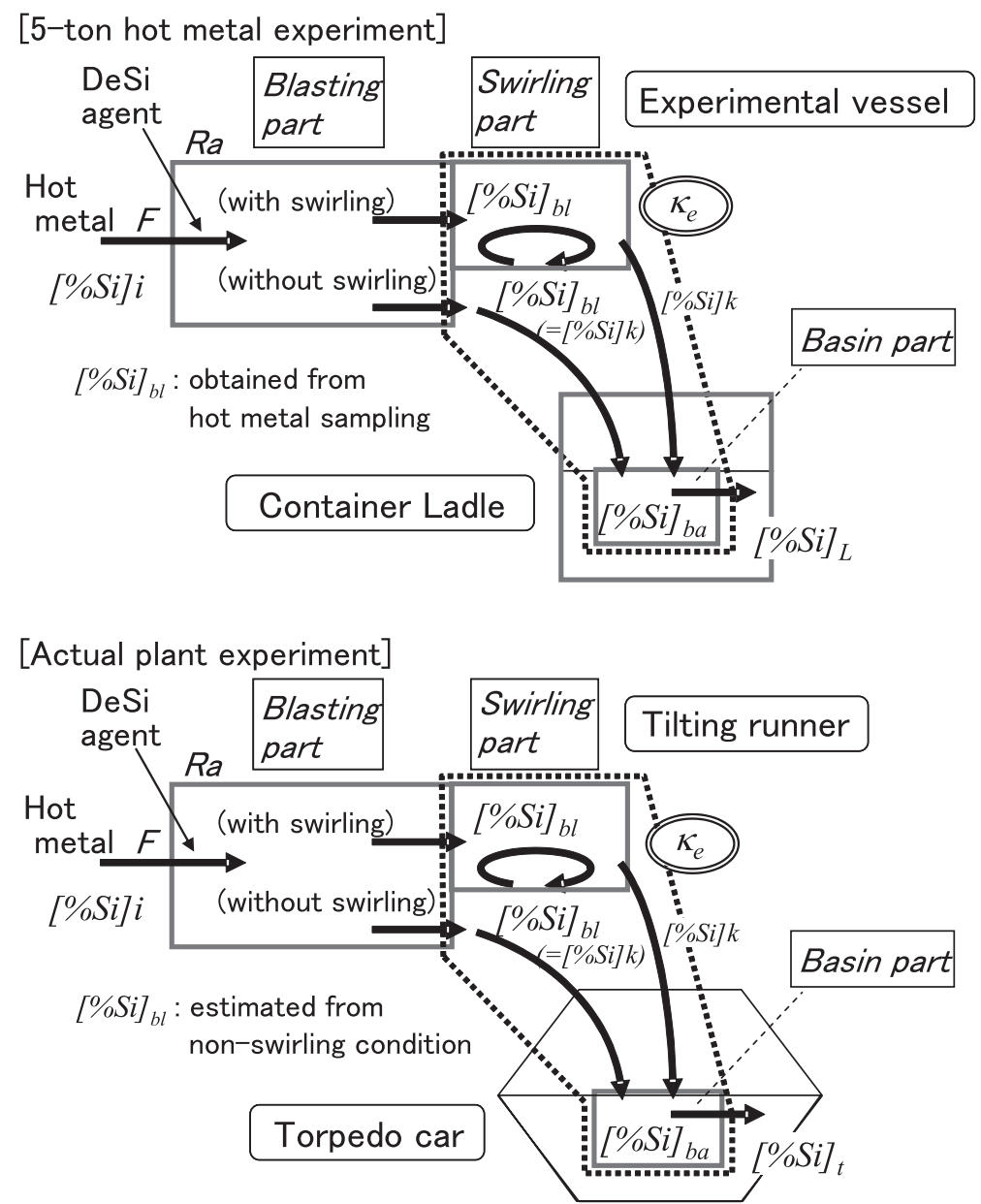

Fig. 15. Schematic reaction models of 5 ton hot metal experiment and actual plant experiment.

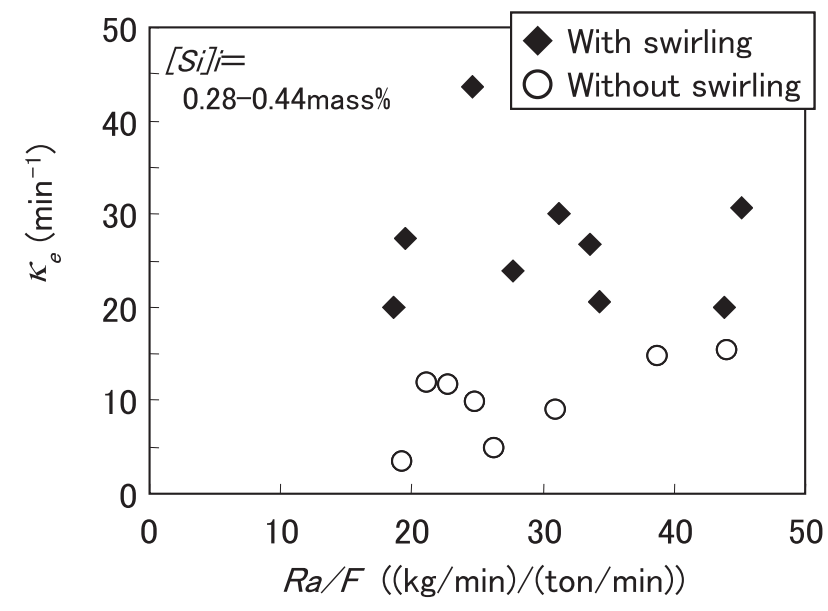

Fig. 16. Relationship between $R a / F$ and $\kappa_{e}$ in 5 ton hot metal experiment. $^{13)}$

results of the previous experiment in Fig. 16, the average value of the rate constant is $10 \mathrm{~min}^{-1}$ for the non-swirling condition and $25 \mathrm{~min}^{-1}$ for the swirling condition, in other words, an increment is 2.5 times. In the results of the present trial in Fig. 17, the average value of the rate constant is 5.9 $\min ^{-1}$ for the non-swirling condition and $13 \mathrm{~min}^{-1}$ for the swirling condition. Thus, the value increased by 2.2 times, which is comparable to the previous result of 2.5 times.

Based on a laboratory-scale experiment, Narita et al. ${ }^{5)}$ reported that desiliconization reaction is determined by both

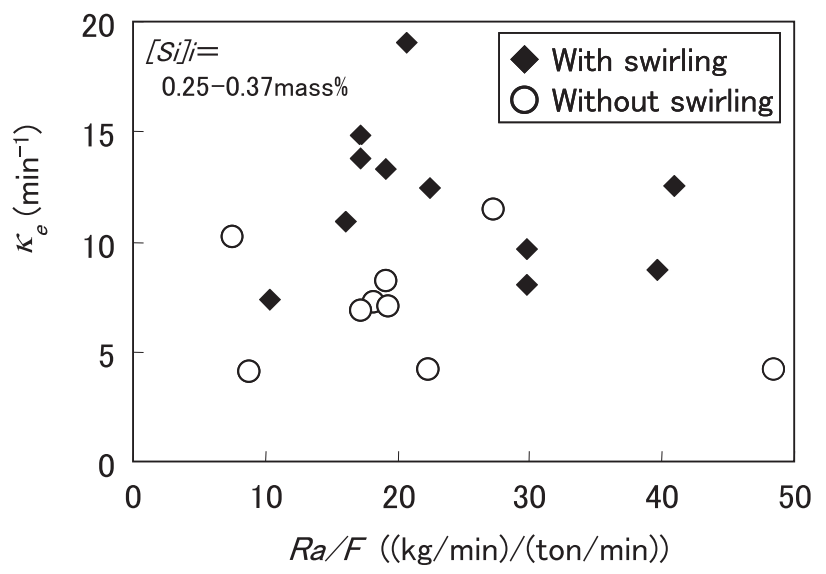

Fig. 17. Relationship between $R a / F$ and $\kappa_{e}$ in present experiments.

mass transfer of silicon in hot metal and mass transfer of $\mathrm{Fe}_{\mathrm{x}} \mathrm{O}$ in slag under the condition that the $\mathrm{Fe}_{\mathrm{x}} \mathrm{O}$ content in the slag is less than 40 mass $\%$. In the present trial, similar low $(\% \mathrm{FexO})$ slag is also involved in the desiliconization reaction in the region from the exit of the blasting part through the basin part of the torpedo car. It is suggested that promotion of reaction in this region by swirling movement was caused by the enhancement of both mass transfer of silicon in metal phase and mass transfer of FexO in slag phase.

Based on the above analysis, silicon content in hot metal after the desiliconization operation in an actual plant was 
estimated. The reaction rate constant of desiliconization obtained above was used for this estimation, as well as multiple regression of the actual plant data. The assumed conditions were 2.5 ton/min as the tapping rate of hot metal, 0.35 mass $\%$ as the silicon content in the tapped hot metal, $20 \mathrm{~kg} /$ ton as the feed rate of desiliconizing agent, $60 \mathrm{~min}$ as the duration of receiving of hot metal in the torpedo car, and 50 min as the duration of feeding desiliconizing agent. Under these conditions, the silicon content after desiliconizing operation is estimated as 0.22 mass $\%$ without swirling of hot metal, and as 0.18 mass \% with swirling. Consequently, application of swirling flow to hot metal would result in a lower silicon content after desiliconization at a blast furnace casthouse, and would thereby lead to improvement of time or efficiency in following hot metal dephosphorization operation and reduction of slag generation in the BOF.

With respect to long-term application of this method at an actual plant, proper management of several potential problems will be necessary; these include erosion of refractory at the swirling part and blockage of the outlet of the swirling part by masses of skull.

\section{Conclusion}

Aiming at more effective silicon removal, a plant trial at an actual blast furnace casthouse was carried out with a tilting runner that was specially designed to generate a swirling flow of hot metal. The following conclusions were obtained.

(1) Amount of silicon removed from the hot metal and efficiency of desiliconization through the entire desiliconization operation were larger under the swirling flow condition of hot metal compared with conventional non-swirling one at same initial silicon content in hot metal.

(2) Hot metal samples taken at the exit of the tilting runner showed that change in silicon content of hot metal in the tilting runner was larger under swirling condition.

(3) Hot metal samples were also taken from the torpedo car, and desiliconization behavior in a transient basin part of the torpedo car (i.e., before mixing with residual metal in torpedo car) was evaluated. Calculated silicon content in the basin part was also lower under the swirling condition.

(4) A reaction analysis was carried out assuming that the present system is a semi-batch reactor. The reaction rate constant of desiliconization through the swirling part of the tilting runner and the basin part of the torpedo car was 2.2 times higher under the swirling condition. This result agrees qualitatively under the results of previous 5 ton hot metal experiments and reflects the enhanced mixing of the desiliconizing agent and hot metal by swirling flow in an industrial-scale operation.

\section{REFERENCES}

1) K. Shinohara, H. Akizuki, M. Yamazaki, K. Kaneki, Y. Senoh and H. Matsuo: Kawasaki Steel Giho, 19 (1987), 162.

2) T. Uchiyama, K. Takeda, S. Taguchi, K. Shinohara, H. Kato and T. Matsumoto: Kawasaki Steel Giho, 22 (1990), 150.

3) W. Pan, M. Sano, M. Hirasawa and K. Mori: Tetsu-to-Hagané, 74 (1988), 61.

4) K. Iwasaki, K. Yamada, T. Usui, S. Inoue, T. Kitagawa, H. Itoh and R. Nakajima: Proc. 4th Int. Conf. on Injection Metallurgy, MEFOS, Luleå, (1986), 21.

5) K. Narita, T. Makino, H. Matsumoto, A. Hikosaka and K. Katsuda: Tetsu-to-Hagané, 69 (1983), 1722.

6) E. Shibata, T. Sato and K. Mori: Tetsu-to-Hagané, 85 (1999), 639.

7) T. Uchiyama, Y. Hara, K. Takeda, H. Itaya, T. Ito and S. Goto: CAMP-ISIJ, 10 (1997), No. 4, 782

8) K. Yamada: 122nd and 123rd Nishiyama Memorial Seminar, ISIJ, Tokyo, (1988), 183.

9) T. Nakasuga, S. Kimura, T. Mimura, R. Tadai, K. Ito and R. Ono: Steel Res. Int., 80 (2009), 530.

10) S. Yokoya, S. Takagi, K. Sasaki and M. Iguchi: Tetsu-to-Hagané, 90 (2004), 301.

11) H. Nakazato, T. Tanaka, A. Okamoto, M. Aono, T. Usui, S. Yokoya and S. Hara: Tetsu-to-Hagané, 90 (2004), 306.

12) V. D. Gleisberg: Giesserei, 55 (1968), 1.

13) Y. Uchida, S. Nabeshima, Y. Kishimoto and Y. Miki: Tetsu-toHagané, 100 (2014), 331.

14) A. K. Gupta, D. G. Lilley and N. Syred: Swirl Flows, Abacus Press, Preston, (1984).

15) Y. Itoh, S. Sato and Y. Kawauchi: Tetsu-to-Hagané, 67 (1981), 2675.

16) K. Yamada, K. Iwasaki, H. Ito, G. Nakatani and M. Ohtsuki: Tetsuto-Hagané, 71 (1985), 1615.

17) K. Mori, M. Hirasawa, M. Shinkai and A. Hatanaka: Tetsu-toHagané, 71 (1985), 1110.

18) I. Muchi and A. Moriyama: Yakin Han-no Kogaku, Yokendo, Tokyo, (1972), 97 (in Japanese).

19) T. Shimizu, M. Iguchi and N. Tsuda: Tetsu-to-Hagané, 87 (2001), 571.

20) V. A. Yefimov and V. P. Grebenyuk: Physical Methods of Modelling Casting of Metal, Naukova Dumka, Kiev, (1975), 172. 